\title{
Pulmonary gas exchange and educational level: a community study
}

\author{
I. Welle*, G.E. Eide*, A. Gulsvik*, P.S. Bakke*
}

Pulmonary gas exchange and educational level: a community study. I. Welle, G.E. Eide, A. Gulsvik, P.S. Bakke. (C) ERS Journals Ltd 2004.

ABSTRACT: Socio-economic status (SES) is related to increased risk of airway disease in terms of forced expiratory volume in one second (FEV1) and forced vital capacity. No data are available as to what extent SES predicts alveolar function in a general population.

In this cross-sectional study, 1,275 subjects aged 18-73 yrs underwent pulmonary testing, including the single-breath carbon monoxide transfer capacity of the lungs $(T L, C O)$. Educational level was used as an index for SES.

Mean \pm SD $T$ L,CO $\%$ predicted was $97 \%$ among those with primary school education, 99\% among those with secondary school education and $104 \%$ among those with a university degree. In a multiple linear regression analysis, adjusting for age, height, haemoglobin, carboxyhaemoglobin, smoking habits, occupational exposure, FEV1 and body mass index, $T \mathrm{~L}$, CO was significantly related to educational level in males but not in females. Occupational exposure was not significant.

In this study, socio-economic status was found to be an independent determinant of $T \mathrm{~L}, \mathrm{CO}$. Even in an affluent country such as Norway, socio-environmental risk factors may differ based on individuals' SES. Such risk factors may, for instance, be higher exposure to airborne pollutants, poorer housing conditions, or lower consumption of fruit and vegetables. Further exploration is called for.

Eur Respir J 2004; 23: 583-588.
*Dept of Thoracic Medicine, Institute of Medicine, University of Bergen, and ${ }^{\#}$ Centre for Clinical Research, University of Bergen, Bergen, Norway.

\section{Correspondence: I. Welle}

Dept of Thoracic Medicine

Institute of Medicine

University of Bergen

N-5021 Bergen

Norway

Fax: 4755975149

E-mail: ida.welle@med.uib.no

Keywords: Epidemiology gas exchange in the lungs socio-economic status

Received: November 222002

Accepted after revision: December 12003
Various general population studies from Europe [1-3] and North America [4-6] have shown that low socio-economic status (SES) is an independent determinant for diseases of the airways, such as chronic bronchitis and chronic obstructive pulmonary disease (COPD). In the majority of these studies, pulmonary function was assessed with tests of maximum expiratory flow. One may hypothesise that some of the risk factors reflected by low SES may not only damage the respiratory airways but may also affect the alveoli and the gas exchange function of the lungs.

Several studies of working populations have examined the relationship between airborne exposure and level or decline of the single-breath carbon monoxide transfer capacity of the lungs (TL,CO). In some studies [7-9], the observed level of $T \mathrm{~L}, \mathrm{CO}$ was lower among the exposed than the unexposed, while in others $[10,11]$ no significant relationship between exposure and level of TL,CO was found. In a longitudinal study of $T \mathrm{~L}, \mathrm{CO}$ in fire fighters [12], a marked decline in $T \mathrm{~L}, \mathrm{CO}$ was noted, without concomitant changes in forced expiratory volume in one second (FEV1).

To the current authors' knowledge, no data are available as to what extent SES can predict the level of TL,CO in the population at large. Using data from a Norwegian general population survey, the aim of this study was to examine the independent relationship of SES, in terms of educational level and occupational airborne exposure, to level of $T \mathrm{~L}, \mathrm{CO}$, and how these relationships varied by age, sex and smoking habits.

\footnotetext{
Methods

Study population and study design

The study was a two-phase cross-sectional community survey. The methods of selection and the characteristics of the
}

population have been given in detail previously [13]. Briefly, the first phase was conducted in 1985. A questionnaire was mailed to a random sample of 4,992 subjects of a general Norwegian population, aged 15-70 yrs, living in the county of Hordaland on the southwest coast of Norway. The response rate was $90 \%$. Based on information obtained from the postal survey, a stratified sample ( $\mathrm{n}=1,512$ subjects) of the respondents living in the city of Bergen or one out of 11 surrounding municipalities was invited to a standardised clinical examination and respiratory physiological examination. The overall attendance rate of those invited was $84 \%$.

The respiratory physiological examination included measurements of $T \mathrm{~L}, \mathrm{CO}$ and spirometric testing.

\section{Transfer factor test and spirometric measurements}

TL,CO was measured using the standard single-breath holding method according to the standardised technique described by COTES et al. [14]. The equipment and the standardised procedure have been described in detail elsewhere $[15,16]$. Measurements of $T \mathrm{~L}, \mathrm{CO}$ were made using a Gould 2001 automated system (Sensor Medics, Bilthoven, the Netherlands). The breath-holding time was preset to $10 \mathrm{~s}$ and the washout volume to $0.75 \mathrm{~L}$. Each subject's height was measured in stockinged feet to the nearest centimetre. Prior to the TL,CO test, each participant was instructed about all the required manoeuvres. The test was performed on the subjects in a sitting position wearing a nose-clip. Each subject performed up to four measurements in order to provide two error-free tests.

Out of the 1,275 subjects who underwent TL,CO measurements, data from 154 were excluded from further analysis for the following reasons: a leak in the sample bag occurred 
during the first 18 days of the study $(n=108)$; some subjects were not able to hold their breath for $10 \mathrm{~s}$ in at least two TL,CO measurements $(n=16)$; some subjects did not fulfil the reproducibility criterion of two tests being within $10 \%$ of each other $(n=25)$; and some subjects performed unsatisfactory spirometric measurements $(n=5)[16]$. The reference equations for $T \mathrm{~L}, \mathrm{CO}$ were derived from a Norwegian, healthy, neversmoking population [15]. Alveolar volume (VA) during breath holding was measured from the single-breath dilution of helium.

Spirometry was also performed, using the Gould 2001 spirometer. The variables recorded included forced vital capacity (FVC) and FEV1. Three technically satisfactory measurements were obtained for each subject, in which FVC was reproducible within $300 \mathrm{~mL}$. A technically satisfactory test met the lung function technical criteria of the European Coal and Steel Community [14].

A venous blood sample was drawn before the transfer test to determine total haemoglobin $(\mathrm{Hb})$ and carboxyhaemoglobin (HbCO) concentrations (SOM3 Hemoximeter; Radiometer, Copenhagen, Denmark).

\section{Clinical examination}

The clinical examination was performed to determine whether or not the subjects had obstructive lung disease, that is, bronchial asthma (BA) or COPD, using diagnostic criteria applied in a previous Norwegian survey [17]. BA was diagnosed in those with a history of attacks of shortness of breath at rest, with wheezing in the chest changing in severity over a short period of time, either spontaneously or after treatment. At least one typical attack had to have occurred within the previous 6 months. COPD was diagnosed in those with a history of chronic cough, phlegm with coughing, breathlessness or wheezing, or both, and a ratio of FEV1 to FVC of $<0.7$.

\section{Educational level and exposure characterisation}

Information on highest educational level was obtained by asking the subjects to state their highest level of schooling attained, from the following three alternatives [18]: 1) former primary school or present 9-yr compulsory school; b) continuation school (3 yrs following compulsory school), lower secondary school, upper secondary school or technical school; or c) college or university.

Occupational exposure was assessed in three ways. First, it was based on self-reported past or present dust or gas exposure in the questionnaire survey [19]. The second assessment was obtained by asking the subjects to state all jobs held since leaving school and lasting $>6$ months. The job titles were grouped on the basis of estimated degree of airborne exposure to dusts, gases or fumes in a typical duty of that particular occupation [13]. The exposure characterisation of each subject was based on present job and longest job held, respectively. The third assessment was based on a structured job history interview by an occupational physician [20]. He asked the participants about their work tasks in each job held since leaving school. For each job, the physician stated whether the participant had been exposed to any airborne pollutants. All subjects who had been exposed to an airborne pollutant for $\geqslant 6$ months were characterised as exposed. The physician was blinded to the results of their TL,CO measurements. All three assessments are independent predictors of obstructive lung disease and respiratory symptoms [13, 19, 20]. They did not differ in their confounding ability in the relationship between education and level of $T \mathrm{~L}, \mathrm{CO}$. Hence, in the remainder of this paper, the occupational airborne characterisation is based on the third assessment.

Nonsmokers were defined as subjects who had never smoked on a daily basis. Ex-smokers were those who had smoked on a daily basis, but who had quit at the time of the study. Subjects were classified as smokers if they smoked daily. Amount of lifetime smoking was assessed as pack-years (number of smoked cigarettes per day $\times$ smoking years/20).

\section{Statistical analysis}

Descriptive statistics were computed by educational level (table 1). The univariate relation of the variables in table 1 to level of education was examined by test for trend analysis. Level of TL,CO was normally distributed in this population. The independent relationship between educational status and level of $T \mathrm{~L}, \mathrm{CO}$ was examined in a linear regression analysis using TL,CO as a response variable, allowing for sex, age, height, smoking status (non-, ex- and current smokers), packyears, $\mathrm{Hb}$ and $\mathrm{HbCO}$ as explanatory variables. Smoking

Table 1.-Characteristics of the study population by educational level in the whole study population

\begin{tabular}{|c|c|c|c|c|}
\hline & Primary school & Secondary school & University & Test for trend ${ }^{\#}$ \\
\hline Subjects $n$ & 208 & 695 & 218 & \\
\hline Males \% & 47 & 51 & 57 & 0.05 \\
\hline Age yrs & $51 \pm 16$ & $40 \pm 16$ & $37 \pm 13$ & $<0.01$ \\
\hline Height $\mathrm{m}$ & $1.69 \pm 10$ & $1.72 \pm 9$ & $1.74 \pm 8$ & 0.02 \\
\hline \multicolumn{5}{|l|}{ Smoking habits $\%$} \\
\hline Nonsmokers & 43 & 55 & 64 & 0.02 \\
\hline Ex-smokers & 18 & 18 & 19 & 0.89 \\
\hline Current smokers & 39 & 27 & 17 & $<0.01$ \\
\hline Smoking consumption pack-yrs & $9.6 \pm 13.3$ & $5.4 \pm 9.6$ & $3.8 \pm 8.3$ & $<0.01$ \\
\hline $\mathrm{HbCO} \%$ of total $\mathrm{Hb}$ & $2.2 \pm 1.8$ & $1.7 \pm 1.4$ & $1.3 \pm 1.0$ & $<0.01$ \\
\hline $\mathrm{Hb} g \cdot \mathrm{L}^{-1}$ & $14.5 \pm 1.1$ & $14.5 \pm 1.3$ & $14.5 \pm 1.3$ & 0.86 \\
\hline COPD $\%$ & 12.1 & 4.3 & 0.4 & $<0.01$ \\
\hline Bronchial asthma \% & 1.9 & 2.9 & 2.2 & 0.82 \\
\hline$T \mathrm{~L}, \mathrm{CO} \mathrm{mmol} \cdot \mathrm{min}^{-1} \cdot \mathrm{kPa}^{-1}$ & $8.2 \pm 2.2$ & $9.4 \pm 2.5$ & $10.4 \pm 2.6$ & $<0.01$ \\
\hline$T \mathrm{~L}, \mathrm{CO} \%$ pred & $99 \pm 16$ & $100 \pm 15$ & $104 \pm 15$ & $<0.01$ \\
\hline$V A \mathrm{~L}$ & $6.0 \pm 1.2$ & $6.4 \pm 1.3$ & $6.8 \pm 1.3$ & $<0.01$ \\
\hline Occupational dust and gas exposure $\%$ & 41 & 33 & 22 & $<0.01$ \\
\hline
\end{tabular}

Data are presented as mean \pm SD or \%. HbCO: carboxyhaemoglobin; Hb: haemoglobin; COPD: chronic obstructive pulmonary disease; TL,CO: mean single-breath carbon monoxide transfer capacity of the lungs; VA: alveolar volume. ${ }^{\sharp}$ : test for trend was performed by the Chi-squared test. 
Table 2. - Comparison of unadjusted single-breath carbon monoxide transfer test $(T \mathrm{~L}, \mathrm{CO})$ values by occupational exposure and educational level in males and females separately

\begin{tabular}{|c|c|c|c|c|c|c|}
\hline & \multicolumn{2}{|c|}{ Primary school } & \multicolumn{2}{|c|}{ Secondary school } & \multicolumn{2}{|c|}{ University } \\
\hline & Subjects n & $T \mathrm{~L}, \mathrm{CO}$ & Subjects n & $T \mathrm{~L}, \mathrm{CO}$ & Subjects n & $T \mathrm{~L}, \mathrm{CO}$ \\
\hline \multicolumn{7}{|l|}{ Males } \\
\hline Exposed & 86 & $9.4 \pm 2.1$ & 234 & $10.7 \pm 2.4$ & 55 & $11.5 \pm 2.1$ \\
\hline Nonexposed & 13 & $10.2 \pm 2.2$ & 120 & $11.2 \pm 2.1$ & 68 & $12.2 \pm 2.5$ \\
\hline \multicolumn{7}{|l|}{ Females } \\
\hline Exposed & 29 & $7.1 \pm 1.3$ & 39 & $7.9 \pm 1.2$ & 15 & $7.8 \pm 1.9$ \\
\hline Nonexposed & 80 & $6.9 \pm 1.4$ & 302 & $7.9 \pm 1.6$ & 80 & $8.6 \pm 1.4$ \\
\hline
\end{tabular}

Data are presented as mean \pm SD unless otherwise stated.

status and educational level were entered into the equations as dummy variables. Further analyses were performed adding level of FEV1 and body mass index (BMI; weight/height ${ }^{2}$ ) to the model. Additional regression analysis was performed taking $V \mathrm{~A}$ into account. As the relationship between $T \mathrm{~L}, \mathrm{CO}$ and $V$ A varies with height, $V$ A was adjusted for in terms of $V \mathrm{~A} /(\text { height })^{2}[21]$. Two-way interaction terms were included only if the interaction was significantly related to changes in $T$ L, CO (p-value $\leqslant 0.05$ ).

\section{Results}

Twenty-one per cent of the males and $16 \%$ of the females reported having graduated from college or university. Eighteen per cent of the males and $24 \%$ of the females reported education at the primary school level.

In both sexes, the mean values for age decreased with increasing level of education, while an opposite trend was observed for height (table 1). The prevalence of smokers decreased with increasing educational level and was twice as high in those with only primary school as in those having graduated from university. An opposite trend was observed in nonsmokers.

Total smoking consumption, as defined in pack-years, increased with decreasing level of education, and was significantly higher among current smokers and ex-smokers with primary school education. A similar trend was observed for $\mathrm{HbCO}$ in per cent of total $\mathrm{Hb}$.
The prevalence of COPD decreased with increasing educational level (table 1), while the mean level for bronchial asthma did not differ significantly in prevalence by educational level.

Among the subjects exposed to gas and dust in their occupation $(n=363), 24 \%$ had a primary-level and only $13 \%$ had a university-level education. Comparatively, among those who were not exposed $(n=758), 16 \%$ had fulfilled a primary school education and $22 \%$ a university education. Unadjusted mean values for $T \mathrm{~L}, \mathrm{CO}$ and $V \mathrm{~A}$ were lowest for those with primary school education. In the exposed males, as well as in the unexposed, TL,CO increased with educational level (table 2). Furthermore, in each education category, TL,CO was lower in exposed males as compared to the unexposed.

In a multiple linear regression analysis, adjusting for sex, age, height, $\mathrm{Hb}, \mathrm{HbCO}$, smoking category, pack-years and occupational exposure, those with university education had significantly higher levels of $T \mathrm{~L}, \mathrm{CO}$ as compared to those with only primary school education $(\mathrm{p}=0.001)$. A highly significant interaction effect from sex and educational category was noted $(\mathrm{p}<0.01)$. Consequently, the relationship between educational level and $T \mathrm{~L}, \mathrm{CO}$ is given separately for males and females (table 3). A significant increase in TL,CO by educational level was observed in males but not in females. Dust or gas exposure was significantly related to level of in $T \mathrm{~L}, \mathrm{CO}$ in males but not in females.

There was no evidence of statistically significant interactions between the effect of smoking (current and ex- as compared with nonsmokers) and occupational exposure, smoking and education (university and secondary school

Table 3. - Multiple linear regression of mean single-breath carbon monoxide transfer capacity of the lungs ( $T L, C O)$ in males and females with respect to age, height, smoking status, levels of haemoglobin $(\mathrm{Hb})$ and carboxyhaemoglobin $(\mathrm{HbCO})$, educational level, and occupational dust or gas exposure in total population sample

\begin{tabular}{|c|c|c|c|c|c|c|}
\hline & \multicolumn{3}{|c|}{ Males } & \multicolumn{3}{|c|}{ Females } \\
\hline & Estimate & SE & p-value & Estimate & $\mathrm{SE}$ & p-value \\
\hline Intercept & -6.48 & & & -6.02 & & \\
\hline Age & -0.07 & 0.005 & $<0.01$ & -0.05 & 0.004 & $<0.01$ \\
\hline Height & 9.65 & 1.05 & $<0.01$ & 8.22 & 0.83 & $<0.01$ \\
\hline Smoking habits & & & 0.45 & & & 0.23 \\
\hline Ex-smokers & -0.03 & 0.20 & & 0.00 & 0.16 & \\
\hline Current smokers & -0.09 & 0.24 & & -0.25 & 0.19 & \\
\hline Smoking consumption pack yrs & -0.02 & 0.007 & 0.01 & -0.01 & 0.01 & 0.24 \\
\hline $\mathrm{HbCO}$ & -0.34 & 0.07 & $<0.01$ & -0.30 & 0.06 & $<0.01$ \\
\hline $\mathrm{Hb}$ & 0.23 & 0.07 & $<0.01$ & 0.21 & 0.05 & $<0.01$ \\
\hline Educational level $^{\top}$ & & & $<0.01$ & & & 0.35 \\
\hline Secondary school & 0.13 & 0.13 & & -0.03 & 0.12 & \\
\hline University level & 0.78 & 0.22 & & 0.15 & 0.16 & \\
\hline Dust or gas exposure & -0.25 & 0.13 & 0.05 & 0.06 & 0.15 & 0.69 \\
\hline
\end{tabular}

HbCO: carboxyhaemoglobin; Hb: haemoglobin. ${ }^{*}$ : reference category is nonsmokers, with ex and current categorised as dummy variables; ${ }^{\circ}$ : reference category is primary school, with secondary and university categorised as dummy variables. 
Table 4.-Relationship between educational level and mean single breath transfer factor of the lung for carbon monoxide $(T L, C O)$, after adjusting for $F E V_{1}$ and body mass index in addition to the variables included in table 3

\begin{tabular}{|c|c|c|c|c|c|c|}
\hline & \multicolumn{3}{|c|}{ Males } & \multicolumn{3}{|c|}{ Females } \\
\hline & Estimate & $\mathrm{SE}$ & p-value & Estimate & $\mathrm{SE}$ & $\mathrm{p}$-value \\
\hline Educational level $^{\#}$ & & & $<0.01$ & & & 0.30 \\
\hline Secondary school & 0.06 & 0.18 & & -0.06 & 0.12 & \\
\hline University level & 0.61 & 0.21 & & 0.09 & 0.16 & \\
\hline Educational level** & & & $<0.01$ & & & 0.33 \\
\hline Secondary school & 0.06 & 0.17 & & -0.03 & 0.12 & \\
\hline University level & 0.60 & 0.22 & & 0.15 & 0.16 & \\
\hline
\end{tabular}

\#: adjusted for age, height, smoking status, pack-years, levels of haemoglobin $(\mathrm{Hb})$ and carboxyhaemoglobin (HbCO), dust/gas exposure and FEV1; ${ }^{\natural}$ : adjusted for age, height, smoking status, packyears, levels of $\mathrm{Hb}$ and $\mathrm{HbCO}$, dust/gas exposure, FEV1 and body mass index.

compared with primary), or occupational exposure and education on the TL,CO function.

Separate analyses were also performed in those $<40$ yrs of age and in those aged $\geqslant 40$ yrs. The relationship between educational level and $T \mathrm{~L}, \mathrm{CO}$ did not differ overtly between the two strata. Stratifying for both age and sex at the same time led to unstable regression coefficients.

In order to assess whether the association of SES with $T$ L,CO was driven by subjects with COPD/asthma, further regression analyses were performed excluding these subjects. The regression coefficients were only slightly affected.

Additional logistic regression analysis was performed adding FEV1 and BMI (table 4). The relationship between education and level of TL,CO was slightly weakened but remained significant in males. The occupational exposure$T \mathrm{~L}, \mathrm{CO}$ relationship was no longer significant after additional adjustment of FEV1 and BMI.

$V \mathrm{~A} /(\text { height })^{2}$ was also added to the original model presented in table 3. The regression coefficients for the educational levels remained overtly the same.

\section{Discussion}

To the current authors' knowledge, this is the first study to examine the association of SES with level of gas-diffusing capacity of the lungs. It was observed that low SES, as measured by educational level, was an independent risk factor for impaired gas exchange in the lungs. This association was higher in males than in females and was not driven by subjects with COPD. Occupational airborne exposure was not independently related to level of $T \mathrm{~L}, \mathrm{CO}$.

There may be several explanations for this finding. Theoretically, poor housing conditions and home dampness, being related to low SES, may not only cause reduced spirometric lung function [3, 22], but also impaired gas diffusion capacity [23]. An increased intake of fish oil and other antioxidant nutrients is related to high SES [24] and may cause higher $T \mathrm{~L}, \mathrm{CO}$ through anti-inflammatory effects on the alveolar membrane [25].

A lower airways infection in childhood is related to impaired spirometric values in adult life [26]. As half the number of alveoli are formed up to the age of 2 yrs and $95 \%$ of the alveolar surface is formed after birth [27], it can be hypothesised that lower airways infections in early life may also impair the gas diffusion capacity. The sex difference found in the present study could partly be explained by the difference in maturation rate of the lungs in young males and females, resulting in different susceptibilities at various stages of childhood. In a Canadian study among 989 primary school children 6-12 yrs of age, the relationship of SES to lung function was reported in young males but not in females [28].

One may argue that the findings of this study could be due to residual confounding by smoking, both active and passive. However, both current smoking, in terms of self-reported smoking habits, and level of $\mathrm{HbCO}$, and previous smoking, in terms of pack-years, were adjusted for. For nonsmokers, level of $\mathrm{HbCO}$ is also an indicator of level of passive smoking. Hence, the finding is not likely to be due to under-adjustment for smoking.

Finally, the finding of this study could be due to residual confounding by occupational airborne exposure, especially since duration of exposure was not measured. However, several forms of occupational exposure characterisations were used, and this made no overt changes to the regression coefficients between socio-economic status and TL,CO. Furthermore, a significant relationship between socioeconomic status and TL,CO persisted in an analysis excluding those who had reported occupational airborne exposure.

The above-mentioned risk factors may have direct adverse effects on the lung parenchyma in adults. Alternatively, as people tend to stay in the social class into which they are born, several of these risk factors may act in childhood to reduce lung growth and cause impaired gas diffusion that sustains into adult life. Such risk factors may include poorer housing conditions, insufficient consumption of fruit and vegetables, and/or higher exposure to airborne pollutants.

As the diffusing capacity is the product of the effective $V \mathrm{~A}$ and the rate of diffusion per unit volume, it could be speculated that the above-mentioned risk factors might work through a reduced $V$ A. However, the relationship between low SES and impaired gas diffusion capacity persisted after adjusting for $\mathrm{VA}$ (in terms of $\mathrm{VA} /$ height $^{2}$ ). This indicates that factors associated with low social class impair the specific gas diffusing capacity. Furthermore, subjects diagnosed with COPD did not drive the association between education and gas diffusing capacity. This disease shows a clear socioeconomic gradient (table 1) and is characterised by reduced $T \mathrm{~L}, \mathrm{CO}$. However, the association persisted even after excluding subjects with COPD. In addition, even after adding level of FEV1 to the model, the relationship between education and $T$ L,CO remained significant (table 4 ).

An important cause of impaired $T \mathrm{~L}, \mathrm{CO}$ is mismatched ventilation/circulation of the lungs. That is, some areas of the lungs may be well ventilated but poorly circulated and vice versa. It may be speculated that a different BMI by educational level might explain such a finding. However, after controlling for BMI, the educational level- $T$ L, CO relationship remained significant (table 4).

There are several advantages of using educational level as an indicator of SES, as compared to using occupational status or income level. Information on educational level is easy to obtain and the accuracy of this information is often higher than that of income [29]. In most subjects, completion of their education predates the onset of the disease. This may not be so for income and occupational status [30]. Consequently, by using educational level, one may reduce the problem of whether the SES is a cause or a consequence of the disease. About half of the studies assessing SES use educational level as an indicator of SES [30]. However, the various indicators of SES capture different aspects of SES [30]. One disadvantage of assessing socio-economic status in terms of educational level is that, in most subjects, educational level is stable over lifetime. Hence, changes in SES over the lifetime will not be noticed using this method. Furthermore, educational level is often measured by number of school years completed. This may vary greatly between various birth cohorts and tends to 
reduce the specificity of educational level as a measure of SES. In this study, this bias was minimised by characterising the subjects not by number of years of education, but by types of schools they had completed. For instance, those who had finished high school, experienced by the older generation and requiring 8-yrs of schooling, were grouped with those who had passed modern technical high school, which requires $12 \mathrm{yrs}$ of schooling. The fact that younger subjects have experienced considerably more formal teaching than older subjects may imply that education is a poorer means of discriminating between social groups in younger than in older subjects.

Educational level may be a poorer predictor of social class in females than in males, as females are more dependent on their husbands' social class than the reverse, especially in older subjects $[30,31]$. This could also explain the finding that the association is stronger in males than in females. As males are more exposed to airborne pollutants than females, a residual confounding by exposure would also work to explain the observed sex difference in the relationship between SES and level of $T \mathrm{~L}, \mathrm{CO}$.

The lack of significant interactions apart from that of sex in the $T \mathrm{~L}, \mathrm{CO}-\mathrm{SES}$ relationship could be due to lack of power. In particular, interaction by age would be interesting to examine in a larger sample than in this study.

The lack of an association between level of TL,CO and occupational airborne exposure, after adjusting for the variables in table 3 as well as FEV1 and BMI, implies either that the cross-sectional study design or the exposure characterisation are not valid enough to detect any association or that the occupational exposure of the general population is not great enough to affect the level of TL,CO. The exposure characterisation used in the present study has previously proved to be a valid instrument to observe significant relationships between occupational airborne exposure and respiratory symptoms and obstructive lung diseases [13, 19, 20]. However, occupational airborne agents causing damage to the airways may not be those responsible for damage of the alveoli, resulting in decreased gas exchange. The site of damage in the lungs by a given physical agent depends in part on its size, its degree of volatility and its solubility in water [32]. To clarify the influence of airborne exposure to level of TL,CO in the community, one might have to use an exposure characterisation specific for agents reaching the alveoli, for instance through a job-exposure matrix [33].

In conclusion, this Norwegian general population survey has observed that low socio-economic status, as measured by low educational level, is an independent risk factor for impaired gas diffusing capacity in males but not in females. The prognostic significance of this difference in single-breath carbon monoxide transfer capacity of the lungs will require a longitudinal study and may eventually work to further explain the reduced life expectancy in lower social classes.

\section{References}

1. Krzyzanowski M, Jedrychowski W, Wysocki M. Factors associated with the change in ventilatory function and the development of chronic obstructive pulmonary disease in a 13-year follow-up of the Cracow Study. Risk of chronic obstructive pulmonary disease (COPD). Am Rev Respir Dis 1986; 134: 1011-1019.

2. Krzyzanowski M, Kauffmann F. The relation of respiratory symptoms and ventilatory function to moderate occupational exposure in a general population. Results from the French PAARC study of 16,000 adults. Int J Epidemiol 1988; 17: 397-406.
3. Prescott E, Vestbo J. Socioeconomic status and chronic obstructive pulmonary disease. Thorax 1999; 54: 737-741.

4. Sherrill DL, Lebowitz MD, Burrows B. Epidemiology of chronic obstructive pulmonary disease. Clin Chest Med 1990; 11: 375-387.

5. Higgins MW, Keller JB, Metzner HL. Smoking, socioeconomic status, and chronic respiratory disease. Am Rev Respir Dis 1977; 116: 403-410.

6. Lebowitz MD. The relationship of socio-environmental factors to the prevalence of obstructive lung diseases and other chronic conditions. J Chronic Dis 1977; 30: 599-611.

7. Polatli M, Erdinc M, Erdinc E, Okyay E. Perlite exposure and 4-year change in lung function. Environ Res A 2001; 86: 238-243.

8. Nur San L, Uysal H, Gökbel H, Seref Bediz C, Sayal A. Pulmonary function of workers in the aluminium industry. Am J Ind Med 1998; 33: 305-307.

9. Carta P, Aru G, Barbieri MT, Avataneo G, Casula D. Dust exposure, respiratory symptoms, and longitudinal decline of lung function in young coal miners. Occup Environ Med 1996; 53: 312-319.

10. Pham QT, Mastrangelo G, Chau N, Haluszka J. Five year longitudinal comparison of respiratory symptoms and function in steelworkers and unexposed workers. Bull Eur Physiopathol Respir 1979; 15: 469-480.

11. Kennedy SM, Wright JL, Mullen JB, Paré PD, Hogg JC. Pulmonary function and peripheral airway disease in patients with mineral dust or fume exposure. Am Rev Respir Dis 1985; 132: 1294-1299.

12. Burgess JL, Brodkin CA, Daniell WE, et al. Longitudinal decline in measured firefighter single-breath diffusing capacity of carbon monoxide values. Am J Respir Crit Care Med 1999; 159: 119-124.

13. Bakke S, Baste V, Hanoa R, Gulsvik A. Prevalence of obstructive lung disease in a general population: relation to occupational title and exposure to some airborne agents. Thorax 1991; 46: 863-870.

14. Cotes JE, Chinn DJ, Quanjer PH, Roca J, Yernault JC. Standardization of the measurement of transfer factor (diffusing capacity). Report Working Party Standardization of Lung Function Tests, European Community for Steel and Coal. Official Statement of the European Respiratory Society. Eur Respir J 1993; 6: Suppl. 16, 41-52.

15. Gulsvik A, Bakke P, Humerfelt S, et al. Single breath transfer factor for carbon monoxide in an asymptomatic population of never smokers. Thorax 1992; 47: 167-173.

16. Welle I, Eide GE, Bakke P, Gulsvik A. Applicability of the single-breath carbon monoxide diffusing capacity in a Norwegian Community Study. Am J Respir Crit Care Med 1998; 158: 1745-1750.

17. Gulsvik A. Prevalence and manifestations of obstructive lung disease in the city of Oslo. Scand J Respir Dis 1979; 60: 286-296.

18. Bakke PS, Hanoa R, Gulsvik A. Educational level and obstructive lung disease given smoking habits and occupational airborne exposure: a Norwegian community study. Am J Epidemiol 1995; 141: 1080-1088.

19. Bakke P, Eide GE, Hanoa R, Gulsvik A. Occupational dust or gas exposure and prevalences of respiratory symptoms and asthma in a general population. Eur Respir J 1991; 4: 273-278.

20. Bakke P, Hanoa R, Gulsvik A. Relation of occupational exposure to respiratory symptoms and asthma in a general population sample: self-reported versus interview-based exposure data. Am J Epidemiol 2001; 154: 477-483.

21. Chinn DJ, Cotes JE, Flowers R, Marks AM, Reed JW. Transfer factor (diffusing capacity) standardized for alveolar volume: validation, reference values and applications of a new linear model to replace Kco (TL/VA). Eur Respir J 1996; 9: 1269-1277.

22. Rasmussen FV, Borchsenius L, Winsløw JB. Associations between housing conditions, smoking habits and ventilatory 
function in men with clean jobs. Scand J Respir Dis 1978; 59: 264-276.

23. Fraser RG, Pare JA, Genereux GP. In: Company SWB, ed. Differential Diagnosis of Diseases of the Chest. Philadelphia, Saunders, 1989; pp. 2361-2385.

24. Johansson L, Thelle DS, Solvoll K, Bjorneboe GE, Drevon CA. Healthy dietary habits in relation to social determinants and lifestyle factors. Br J Nutr 1999; 81: 211-220.

25. Schunemann HJ, Freudenheim JL, Grant JB. Epidemiologic evidence linking antioxidant vitamins to pulmonary function and airway obstruction. Epidemiol Rev 2001; 23: 248-267.

26. Johnston ID. Effect of pneumonia in childhood in adult lung function. J Pediatr 1999; 135: 33-37.

27. Hislop AA, Wigglesworth JS, Desai R. Alveolar development in the human fetus and infant. Early Hum Dev 1986; 13: $1-11$.

28. Demissie K, Ernst P, Hanley JA, Locher U, Menzies D,
Becklake M. Socioeconomic status and lung function among primary school children in Canada. Am J Respir Crit Care Med 1996; 153: 719-723.

29. Susser M, Watson W, Hopper K. Sociology in Medicine New York, Oxford University Press, 1985.

30. Liberatos P, Link BG, Kelsey JL. The measurement of social class in epidemiology. Epidemiol Rev 1988; 10: 87-121.

31. Sacker A, Firth D, Fitzpatrick R, Lynch K, Bartley M. Comparing health inequality in men and women: prospective study of mortality 1986-96. BMJ 2000; 320: 1303-1307.

32. Parkes RW. Aerosols: their deposition and clearance. In: Parkes RW, ed. Occupational Lung Disorders. Oxford, Butterworth-Heinemann Ltd, 1994; pp. 35-49.

33. Tielemans E, Heederik D, Burdof A, et al. Assessment of occupational exposures in a general population: comparison of different methods. Occup Environ Med 1999; 56: 145151. 